\title{
METODE MARKERLESS UNTUK MEMBANGUN APLIKASI PEMANDU WISATA WILAYAH CIAYUMAJAKUNING BERBASIS MOBILE ANDROID
}

\author{
Oleh : \\ Selvia Lorena Br Ginting ${ }^{1}$, Meylly Pamungkas ${ }^{2}$, Yogie Rinaldy Ginting ${ }^{3}$ \\ Universitas Komputer Indonesia ${ }^{1,2}$, Universitas Riau/PhD Student at Curtin \\ University \\ Email: selvialorena@yahoo.com
}

\begin{abstract}
ABSTRAK
Ciayumajakuning, memiliki banyak jenis wisata menarik yang ditawarkan seperti wisata alam, wisata budaya, sampai wisata sejarah, yang diharapkan dapat menarik wisatawan domestik maupun mancanegara. Bagi setiap wisatawan yang baru pertamakali akan berkunjung ke wilayah Ciayumajakuning tentunya sangat membutuhkan informasi dan data mengenai lokasi-lokasi wisata yang berada di wilayah Ciayumajakuning, serta rute untuk mencapainya. Penggunaan peta dan pemandu wisata (tour guide), dapat menjadi solusi bagi para wisatawan yang baru pertama kali berkunjung ke wilayah Ciayumajakuning agar dapat memberikan informasi-informasi yang dibutuhkan oleh wisatawan tersebut, tetapi peranan pemandu wisata dan peta terkadang tidak cukup dan tidak memberikan informasi yang sesuai dengan yang dibutuhkan oleh wisatawan tersebut. Untuk menggantikan peran pemandu wisata dan peta tersebut, maka dibangun sebuah aplikasi pemandu wisata yang dapat memberikan informasi kepada wisatawan mengenai objek wisata yang terdapat di wilayah Ciayumajakuning beserta rute untuk mencapainya. Agar solusi tersebut dapat dicapai maka sistem ini akan dipasang pada smartphone Android. Aplikasi ini mengimplementasikan teknologi Augmented Reality (AR). Selain itu aplikasi yang dibangun mencakup data-data yang biasanya dibutuhkan oleh wisatawan yaitu informasi posisi wisatwan berada, informasi objek wisata, jarak dari posisi wisatawan berada dengan posisi objek wisata, rute dan informasi waktu tempuh, serta objek-objek penting yang terdapat dalam perjalanan.
\end{abstract}

Kata kunci :Objek Wisata, Ciayumajakuning, Wisatawan, Augmented Reality

\section{PENDAHULUAN}

Ciayumajakuning (Kota Cirebon, Kabupaten Cirebon, Kabupaten Indramayu, Kabupaten Majalengka dan Kabupaten Kuningan) merupakan kekuatan ekonomi yang baru dan besar di Jawa Barat setelah kawasan Bandung Raya. Sektor pariwisata menjadi salah satu andalan wilayah ini, untuk itu diperlukan peningkatan pelayanan pada sektor ini sehingga diharapkan dapat meningkatan perekonomian masyarakat Ciayumajakuning. Ciayumajakuning, memiliki banyak jenis wisata menarik yang 
ditawarkan seperti wisata alam, wisata budaya, sampai wisata sejarah, yang diharapkan dapat menarik wisatawan domestik maupun mancanegara.

Bagi wisatawan yang baru pertama kali akan mengunjungi tempat wisata yang terdapat di wilayah Ciayumajakuning. Seringkali muncul masalah dalam memperoleh informasi, seperti lokasi objek wisata dan rute untuk mencapainya. Berbagai cara dapat dilakukan untuk mendapatkan informasi akan objek wisata, seperti misalnya penggunaan jasa pemandu (guide), peta, bertanya ke orang-orang yang ditemui dan lain-lain. Namun dengan cara tersebut terkadang tidak cukup dan tidak memberikan informasi yang sesuai dengan yang dibutuhkan oleh calon wisatawan. Dengan adanya aplikasi Pemandu Wisata diharapkan dapat memudahkan wisatawan untuk mendapatkan informasi yang dibutuhkan mengenai objek wisata yang ada di wilayah Ciayumajakuning.

Tujuan dari penelitian ini adalah aplikasi Pemandu Wisata yang dapat memberikan informasi rute, jarak dan estimasi waktu tempuh untuk mencapai lokasi wisata yang dituju, serta menarik minat wisatawan sebanyak-banyaknya untuk berkunjung ke wilayah Ciayumajakuning sehingga jumlah wisatawan meningkat, dengan demikian program pemerintah dalam meningkatkan pelayanan dibidang pariwisata untuk meningkatkan Pendapatan Asli Daerah (PAD) dapat tercapai. Metode untuk membangun aplikasi Pemandu Wisata ini adalah dengan mengimplementasikan teknologi Augmented Reality (AR) yang diintegrasikan dengan data POI (Point of Interest) yang menampilkan posisi lokasi suatu ojek dalam bentuk simbol secara nyata dari aplikasi smartphone.

\section{TEORI PENUNJANG}

\subsection{Augmented Reality}

Augmented Reality adalah penggabungan objek-objek digital baik itu berupa dua dimensi maupun tiga dimensi dengan dunia nyata yang lalu memproyeksikan bendabenda maya tersebut dalam waktu nyata (real time). [13] Objek-objek digital yang menampilkan informasi tidak dapat diterima pengguna oleh inderanya sendiri. Informasi yang ditampilkan oleh objek-objek digital hanya sebagai alat yang membantu persepsi dan interaksi penggunanya dengan dunia nyata. Sehingga informasi tersebut membantu penggunanya melaksanakan kegiatan dalam dunia nyata. [1]

\subsection{Pariwisata}

Wisata adalah kegiatan perjalanan yang dilakukan oleh seseorang atau sekelompok orang dengan mengunjungi tempat tertentu untuk tujuan rekreasi, pengembangan pribadi, atau mempelajari keunikan daya tarik wisata yang dikunjungi dalam jangka waktu sementara. [5]

\subsection{Android}

Android merupakan sistem operasi yang ditujukan pada perangkat bergerak (mobile) baik itu berupa handphone maupun netbook. Android dibangun diatas Linux Kernel yang memberikan keterbukaan dari sisi pengembang, sehingga developer pengembang Android tidak hanya untuk kalangan tertentu saja. [1][5][16] 
Pada awalnya, Google Inc. membeli Android Inc. yang merupakan pendatang baru yang membuat piranti perangkat lunak untuk smartphone. Kemudian untuk mengembangkan Android, maka dibentuk Open Handset Alliance (OHA), konsoriun dari 34 perusahaan perangkat keras, perangkat lunak, dan telekomunikasi, termasuk Google, HTC, Intel, Motorola, Qualcom, T-Mobile, dan Nvidia. [13]

\subsection{Android Studio}

Android Studio merupakan sebuah Integrated Development Environment (IDE) khusus untuk membangun aplikasi yang berjalan pada platform android. Android studio ini berbasis pada IntelliJ IDEA, sebuah IDE untuk Bahasa pemrograman Java. Bahasa pemrograman utama yang digunakan adalah Java, sedangkan untuk membuat tampilan atau layout, digunakan bahasa XML. Android studio juga terintegrasi dengan Android Software Development Kit (SDK) untuk deploy ke perangkat android. [3]

\subsection{Google Maps API}

Google Maps API merupakan salah satu Application Programming Interface (API) yang dimiliki oleh Google. API ini memiliki fitur untuk melakukan aktivitasaktivias yang berkaitan dengan Google Maps, antara lain menampilkan peta, mencari rute terdekat antara dua tempat, dan lain sebagainya. Google Maps API tersedia untuk platform android, iOS, web, dan juga web service. [3]

Google Maps API adalah API yang paling populer di internet. Pencatatan yang dilakukan pada bulan Mei tahun 2010 ini menyatakan bahwa 43\% mashup (aplikasi dan situs web yang menggabungkan dua atau lebih sumber data) menggunakan Google Maps API. [16]

\subsection{LBS (Location Based Service)}

LBS merupakan sebuah layanan yang menyediakan informasi dengan menggunakan informasi geografis yang ada pada sebuah perangkat. [3] Dengan menggunakan location based service, perangkat akan menentukan lokasinya, dan informasi ini digunakan untuk mendapatkan informasi berguna lainnya untuk user. [16]

LBS sendiri memiliki arti dalam bahasa indonesia adalah layanan berbasis lokasi, yaitu layanan informasi yang didasarkan pada lokasi pengguna saat itu berada. Sistem pada LBS mampu bereaksi aktif pada perubahan entitas posisi dan memberikan informasi letak objek di sekitar pengguna berada. Informasi yang disediakan LBS antara lain: [13]

1. Latitude (Sudut Jarak dari Khatulistiwa)

2. Bujur (Sudut Jarak dari Greenwich Meridian)

3. Ketinggian (Di Atas Permukaan Laut)

4. Orientasi (Sudut Jarak dari Utara Tiang)

\section{ANALISIS DAN PERANCANGAN SISTEM}

\subsection{Analisis Kebutuhan Sistem}

Sebelum melakukan perancangan sistem, terlebih dahulu dilakukan analisis kebutuhan sistem yaitu dengan cara melakukan wawancara terhadap responden. Hal ini 
dimaksudkan agar dapat mengatasi ketidaksesuaian antara aplikasi yang dirancang dengan kebutuhan pengguna. Adapun kebutuhan sistem yang diperlukan antara lain:

1. Memberikan informasi keberadaan POI (Point of Interest) objek-objek penting bagi pengguna dengan visualisasi augmented reality.

2. Menampilkan informasi data POI (Point of Interest) mengenai tempat-tempat wisata yang terdapat di wilayah Ciayumajakuning dengan visualisasi augmented reality.

3. Mengukur jarak tempuh ke lokasi wisata yang akan dituju dari posisi pengguna saat itu berada.

4. Memberikan estimasi waktu tempuh ke lokasi wisata yang akan dituju dari posisi pengguna saat itu berada.

5. Menampilkan navigasi dari lokasi pengguna berada sampai lokasi tujuan.

\subsection{Pemodelan Sistem}

Pemodelan sistem aplikasi yang dibangun dimodelkan dengan menggunakan UML (Unified Modeling Language). Pemodelan disini merupakan penggambaran diagram model yang terdiri dari diagram Use Case diagram, Class diagram, Sequence diagram, dan collaboration diagram.

\subsubsection{Use Case Diagram}

Digunakan untuk memodelkan atau menggambarkan batasan sistem dan fungsifungsi utamanya. Mendiskripsikan fungsi dari sebuah sistem dari perspektif pengguna, use case bekerja dengan cara mendeskripsikan tipikal interaksi antara pengguna sebuah sistem dengan sistemnya sendiri melalui gambaran bagaimana sebuah sistem digunakan. Use case terdiri dari tiga bagian yaitu definisi actor, definisi use case, dan scenario use case.

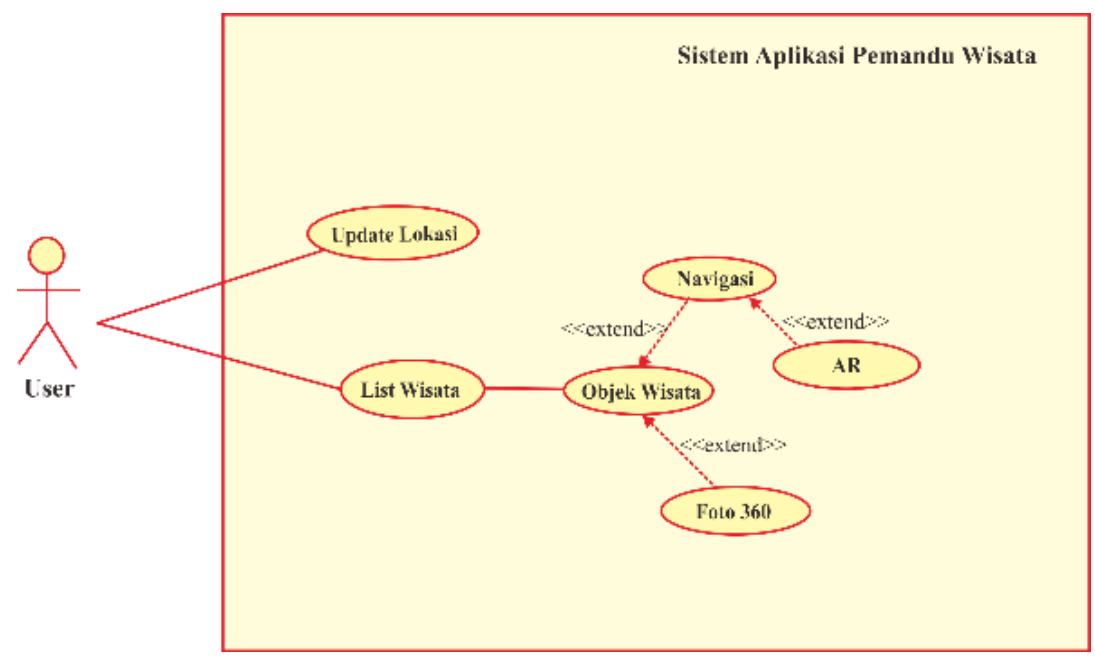

Gambar 1. Use Case Diagram 


\subsubsection{Collaboration Diagram}

Menjelaskan interaksi objek yang disusun dalam suatu urutan waktu. Diagram secara khusus bersosialisasi dengan use case. Collaboration diagram, memperlihatkan tahap demi tahap yang seharusnya terjadi untuk menghasilkan sesuatu dalam use case.

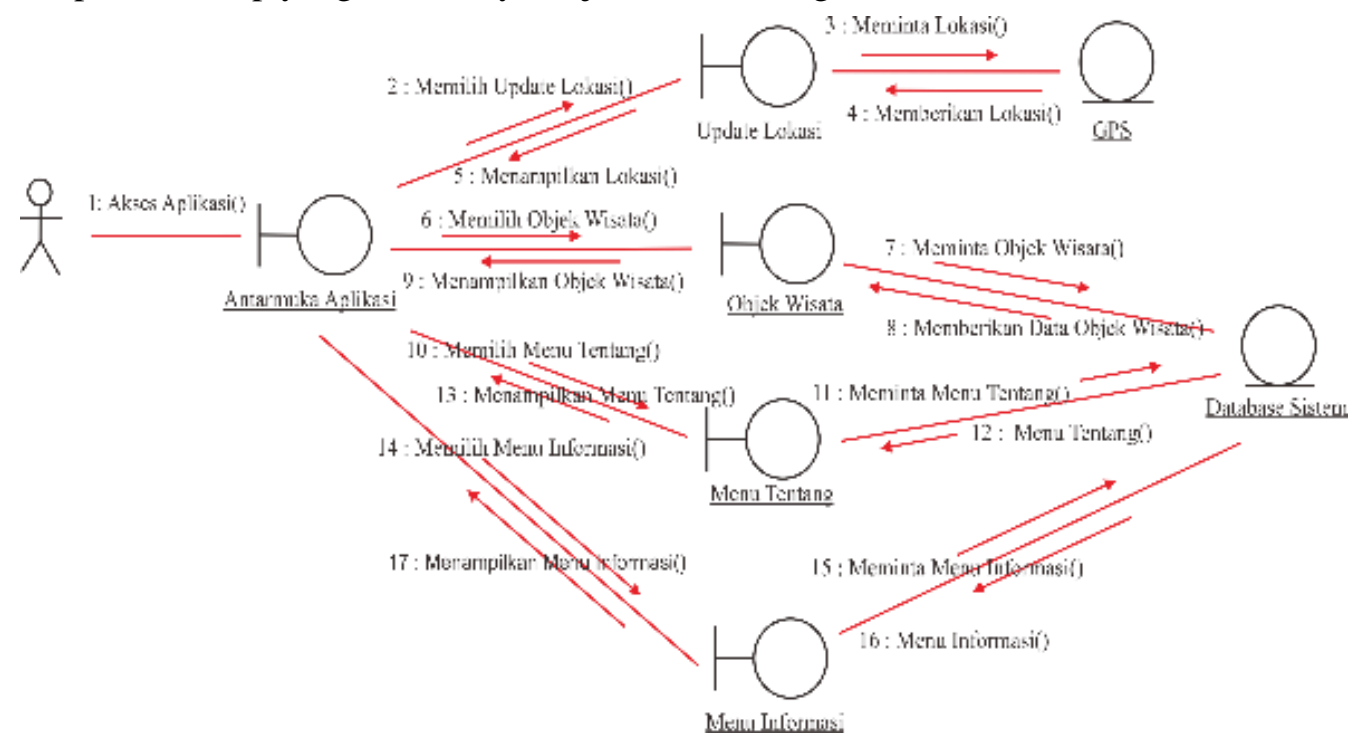

Gambar 2. User Collaboration Diagram

\subsection{Perancangan Arsitektural}

Perancangan arsitektural merupakan perancangan yang dibuat untuk mengarahkan peneliti terhadap konsep yang akan diterapkan pada aplikasi yang akan dibangun. Hal ini dapat dilihat pada Gambar 3.

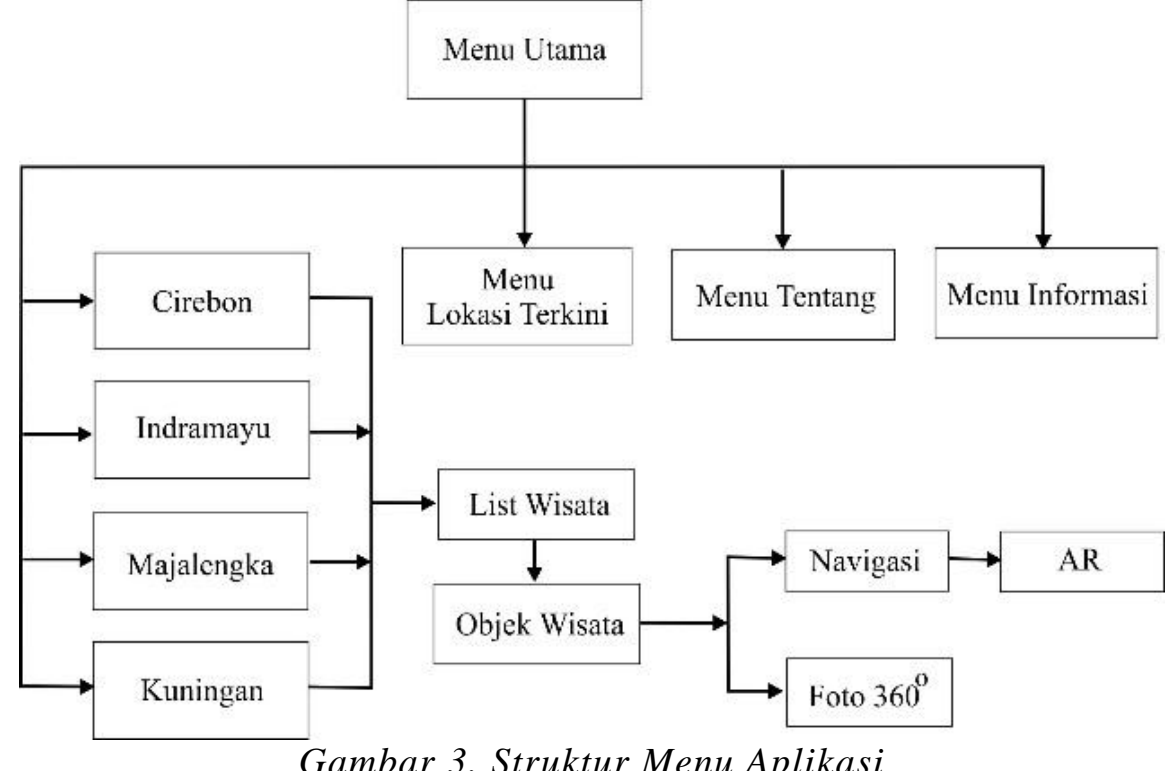

Gambar 3. Struktur Menu Aplikasi

Gambar 3 menunjukkan struktur menu aplikasi yang akan dibangun. Fungsi dari struktur menu digunakan untuk mendefinisikan dan mengilustrasikan sistem secara 
berjenjang dalam bentuk menu dan sub menunya. Dimana pada aplikasi ini memiliki beberapa pilihan menu, setiap menu memiliki isi maupun informasi yang berbeda pada setiap sub menunya

\subsection{Perancangan Prosedural}

Perancangan prosedural merupakan perancangan yang dibuat untuk menetapkan algortima yang akan diterapkan didalam sistem. Perancangan prosedural sendiri digambarkan dalam flowchart, yang digambarkan di bawah ini:

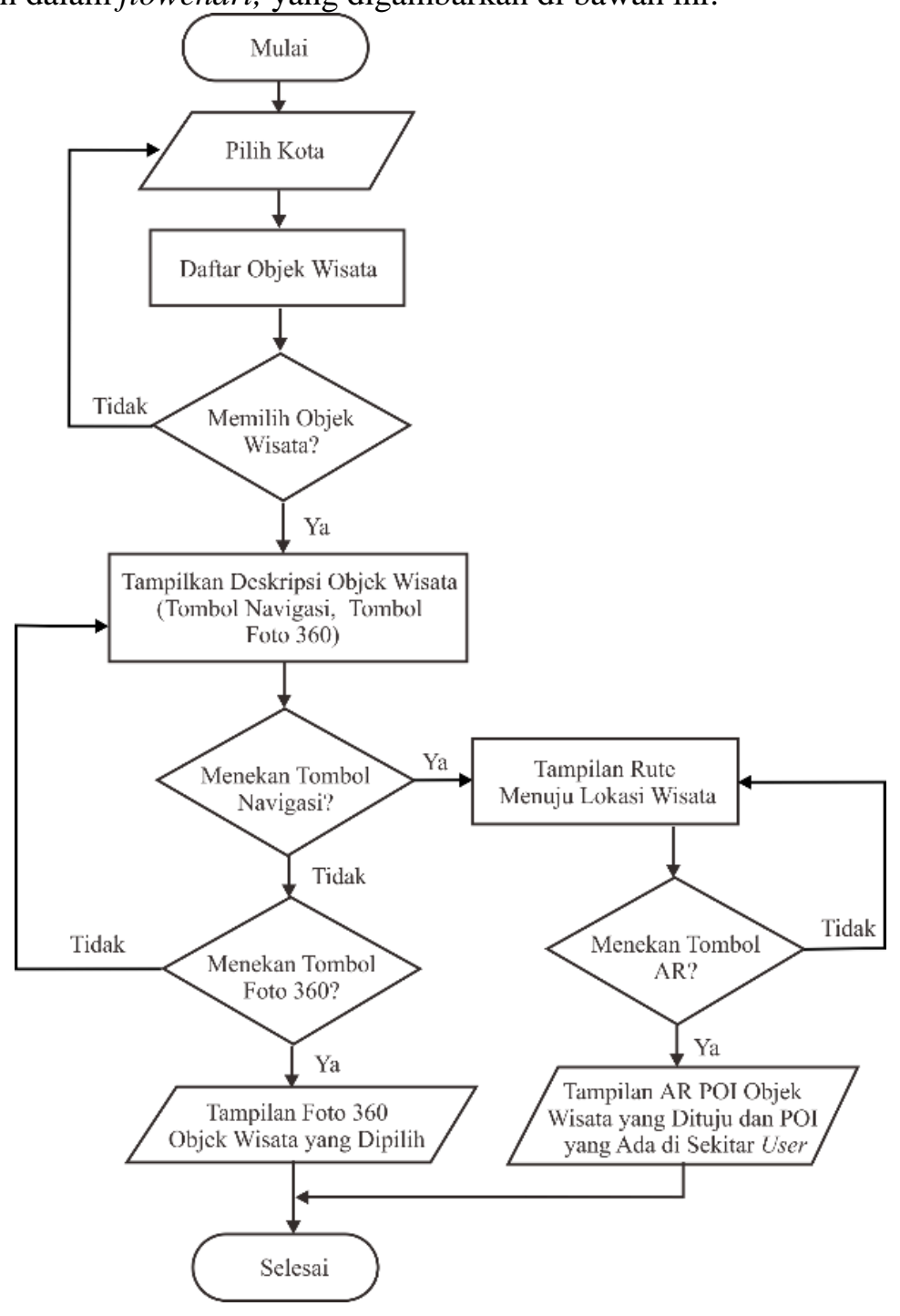

Gambar 4. Flowchart Sistem

Berdasarkan pada flowchart tersebut, user melakukan pemilihan kota (Cirebon, Indramayu, Majalengka, Kuningan). Kemudian user akan disajikan daftar objek wisata dari kota yang dipilih. Pada bagian tersebut user dapat memilih objek wisata yang sekirannya diminati, jika user tidak memilih objek wisata maka user dapat kembali lagi ke menu utama (kategori kota). Sedangkan jika user memilih salah satu objek wisata, 
maka aplikasi akan mengirimkan data informasi objek wisata sesuai dengan objek wisata yang telah dipilih oleh $u$ ser.

\section{IMPLEMENTASI DAN PENGUJIAN}

\subsection{Implementasi}

Antarmuka aplikasi terdiri dari beberapa halaman utama, yaitu halaman menu utama, halaman lokasi terkini user, halaman deskripsi, halaman informasi, halaman list lokasi wisata, halaman detail lokasi wisata, halaman navigasi (view on map), halaman augmented reality.

1. Halaman Menu Utama

Merupakan menu utama dari aplikasi. Dimana pada bagian ini terdapat beberapa menu yang tersedia yang dapat dipilih oleh user.
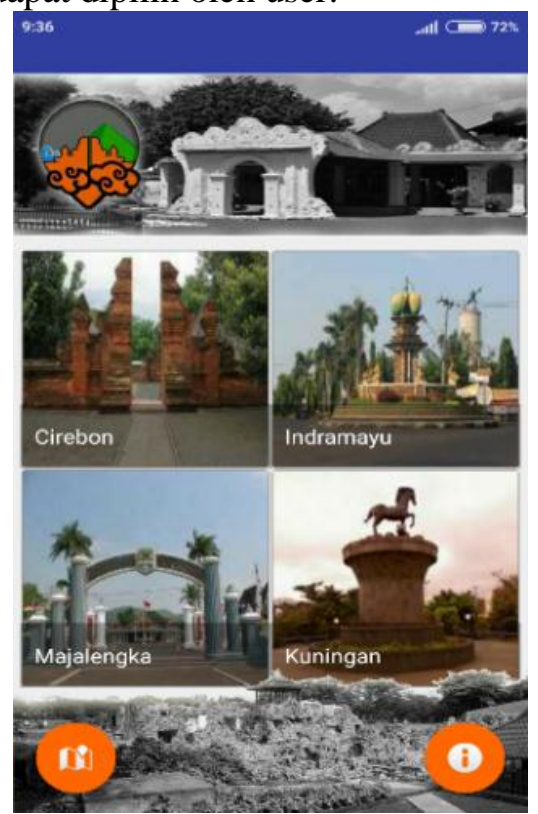

Gambar 5. Halaman Menu Utama

Pada gambar 6 merupkan halaman utama yang pertama tampil saat user mengaktifkan atau menjalankan aplikasi. Pada antarmuka ini terdapat menu daerah (Cirebon, Indramayu, Majalengka, Kuningan), menu lokasi terkini, menu deskripsi, dan menu informasi yang dapat diakses oleh User.

2. Halaman List Lokasi Wisata

Halaman list lokasi wisata adalah halaman antarmuka untuk fungsionalitas menampilkan list lokasi wisata dari daerah yang dipilih. 


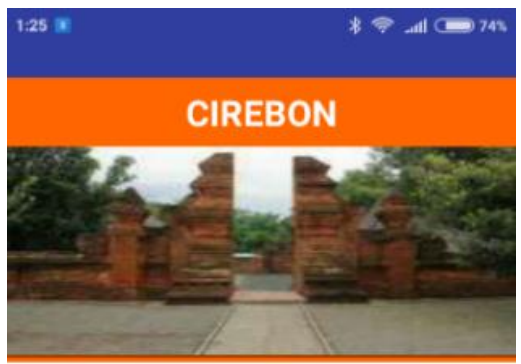

\section{GOA SUNYARAGI}

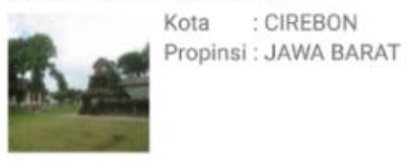

\section{KERATON KESEPUHAN}

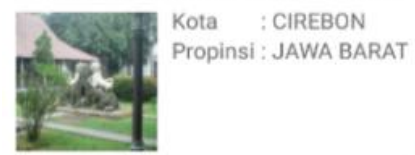

\section{ADE IRMA SURYANI}

Gambar 6. Halaman List Lokasi Wisata Cirebon

Pada gambar 7 menunjukkan tampilan dari list lokasi wisata. Dimana untuk menampilkan list lokasi wisata ini, user harus memilih daerah yang akan dituju terlebih dahulu pada bagian menu utama (gambar 5). Pada halaman ini user dapat memilih lokasi wisata yang akan dikunjungi.

3. Halaman Objek Wisata yang Dipilih

Halaman objek wisata yang dipilih adalah halaman antarmuka untuk fungsionalitas menampilkan detail lokasi wisata. Pada halaman antarmuka ini memberikan informasi tambahan mengenai tempat wisata yang dipilih sebelumnya. 


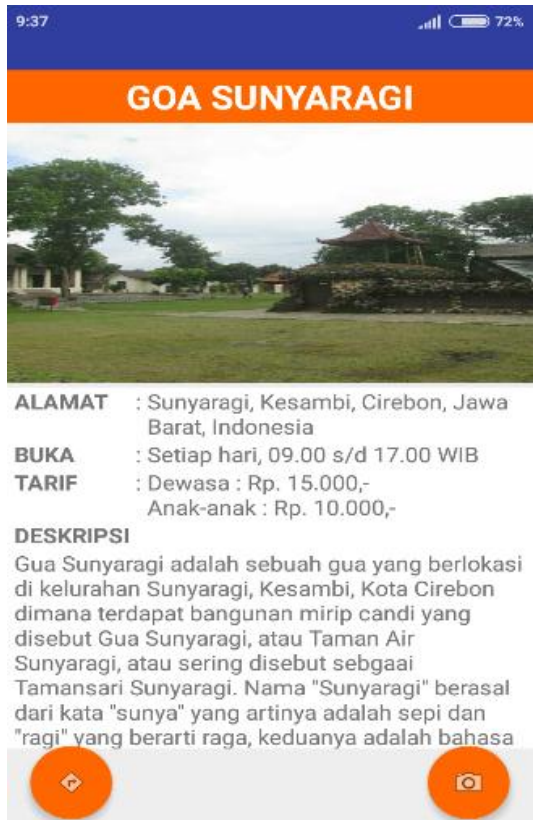

Gambar 7. Halaman Detail Lokasi Wisata

Pada gambar 7. Menunjukkan detail lokasi wisata yang dipilih. Dimana pada halaman ini terdapat alamat, jam buka, tarif, dan deskripsi dari lokasi wisata yang dipilih oleh user. Selain itu pada halaman ini juga terdapat beberapa tombol yang dapat dipilih oleh user seperti tombol navigasi, tombol AR, dan tombol photo $360^{\circ}$ dari lokasi wisata tersebut.

4. Halaman Navigasi

Halaman Navigasi adalah halaman antarmuka untuk fungsionalitas menampilkan rute perjalanan menuju objek wisata yang dituju.

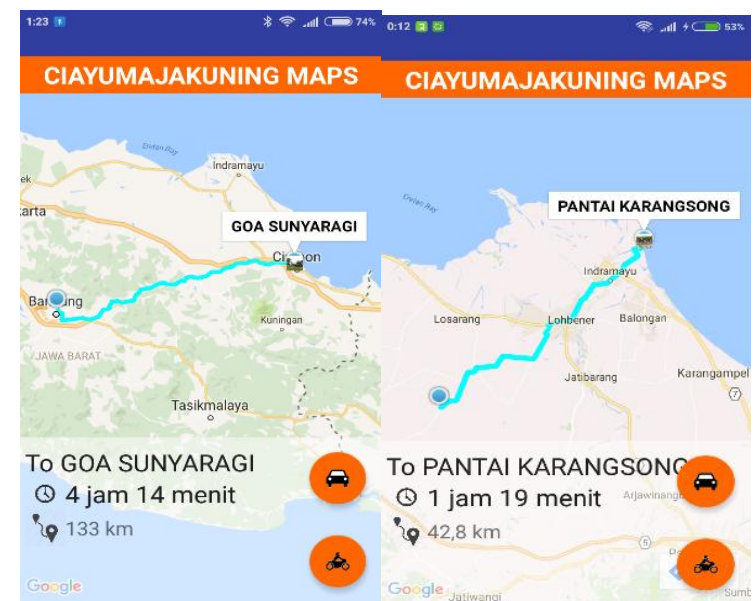

(a)

Gambar 8. Halaman Navigasi. (a) Rute Menuju Goa Sunyaragi, (b) Rute Menuju Pantai Karangsong

Pada gambar 8 ditunjukkan sebuah rute navigasi untuk menuju lokasi wisata yang akan dituju. Rute navigasi diambil dari titik lokasi keberadaan user saat itu berada. Pada 
halaman navigasi ini selain menampilkan rute perjalanan juga terdapat estimasi waktu dan jarak tempuh yang dibutuhkan.

1. Halaman Augmented Reality

Halaman augmented reality adalah halaman antarmuka untuk fungsionalitas menampilkan bentuk augmented reality dari lokasi wisata dan POI yang akan ditemui dalam perjalan.

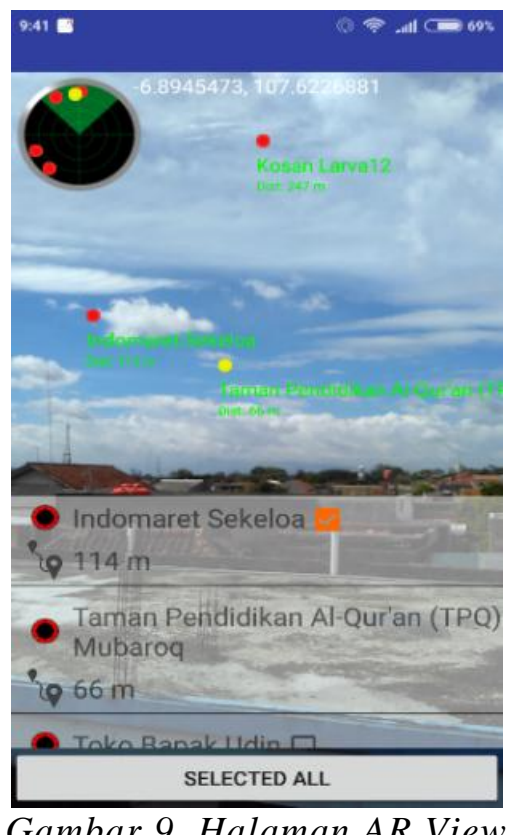

Gambar 9 menunjukkan tampilan augmented reality ketika user memilih tombol AR pada halaman navigasi.

\subsection{Pengujian}

\subsubsection{Pengujian Alpha}

Pengujian dilakukan terhadap aplikasi untuk memastikan bahwa aplikasi dapat berjalan dengan benar sesuai dengan kebutuhan dan tujuan yang diharapkan. Pengujian berfokus pada persyaratan fungsionalitas aplikasi.

Berdasarkan hasil pengujian alpha yang telah dilakukan dapat ditarik kesimpulan bahwa sistem yang dibangun sudah berjalan sesuai dengan perancangan awal dan sitem juga dapat menghasilkan keluaran sesuai dengan yang diharapkan. Tetapi tidak menutup kemungkinan suatu saat dapat terjadi kesalahan, pada saat aplikasi digunakan. Sehingga membutuhkan proses perawatan dan pengecekan (maintenance) untuk menjaga agar aplikasi tetap berjalan sesuai dengan yang diharapkan. Kelebihan dari aplikasi ini yaitu kemungkinan untuk memperbaharui data dapat dilakukan secara rutin. Sehingga infromasi yang diterima lebih tepat dan cepat karena aplikasi menggunakan sambungan internet (online), memberikan informasi penting tentang objek wisata yang akan dikunjungi. Kelemahannya adalah pada kecepatan koneksi internet, ketika koneksi internet lambat atau bahkan tidak terdapat jaringan internet, maka untuk pembaharuan data tidak dapat dilakukan, serta pada bagian menu navigasi dan menu AR akan 
terhambat. Selain itu aplikasi ini juga hanya dapat dijalankan pada smartphone android saja.

\subsubsection{Pengujian Markerless Augmented Reality}

Berikut merupakan pengujian yang dilakukan pada aplikasi pemandu wisata wilayah Ciayumajakuning, yaitu pengujian ketepatan titik lokasi pada kamera (markerless augmented reality) dengan dunia nyata. Pengujian ini dilakukan untuk menunjukkan keakuratan sistem dengan keadaan yang sebenarnya saat user menggunakan aplikasi. Sampel pengujian diambil pada kasus user mencari lokasi keraton Kasepuhan Cirebon.

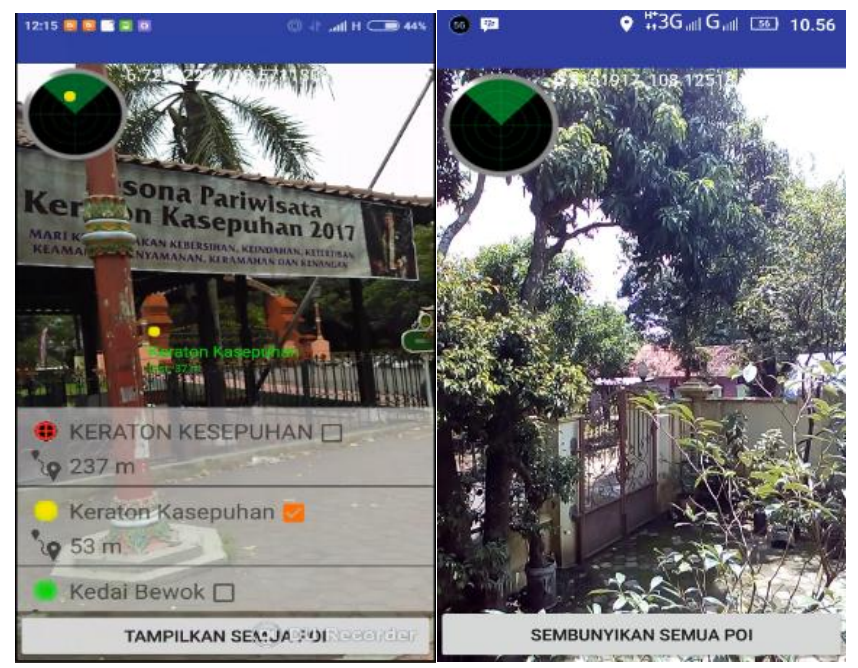

(a)

(b)

Gambar 10. (a) memiliki sensor kompas (b) tanpa sensor kompas

Pada gambar diatas dapat dilihat bahwa tampilan markerless augmented reality. Gambar 10. (a) menunjukkan POI keraton Kasepuhan ketika user mengarahkan kamera langsung ke arah keraton Kasepuhan. Sedangkan pada gambar 10. (b) menunjukkan bahwa smartphone yang tidak memiliki sensor kompas di dalamnya tidak dapat menampilkan POI yang berada disekitar user berada.

\section{KESIMPULAN DAN SARAN}

\subsection{Kesimpulan}

Berdasarkan hasil implementasi dan pengujian sistem pada aplikasi pemandu wisata wilayah Ciayumajakuning, maka dapat diambil kesimpulan sebagain berikut:

1. Dengan aplikasi ini dapat membantu calon wisatawan untuk mendapatkan informasi secara lengkap mengenai lokasi wisata yang akan dikunjungi. Karena pada aplikasi ini terdapat rincian mengenai lokasi wisata yang sekiranya diperlukan oleh wisatawan seperti deskripsi lokasi wisata, harga tiket masuk, dan jam buka tempat wisata tersebut. Hal ini dapat dilihat dari hasil kuesioner pada pertanyaan nomor 3 dimana pada pertanyaan tersebut mendapatkan nilai presentase $90 \%$ dari $100 \%$ atau dapat juga dikategorikan user sangat setuju dengan 
pertanyaan nomor 3 bahwa aplikasi dapat memberikan informasi tempat-tempat wisata di Ciayumajakuning.

2. Menjadi alternatif lain sebagai pemandu wisata khususnya di wilayah Ciayumajakuning. Dengan adanya aplikasi ini, wisatawan yang berasal dari luar kota tidak perlu lagi menggunakan peta atau bertanya kepada warga yang ditemui di jalan saat menuju lokasi wisata. Karena pada aplikasi ini terdapat fitur navigasi untuk menunjukan rute menuju lokasi wisata yang akan dituju. Hal ini dapat dilihat dari hasil kuesioner pada pertanyaan nomor 2 dan 6 dimana pada pertanyaan tersebut masing-masing mendapatkan nilai presentase $87 \%$ dan $88 \%$ dari $100 \%$ atau dapat juga dikategorikan user sangat setuju dengan pertanyaan nomor 2 dan nomor 6 bahwa aplikasi dapat memberikan informasi tempat-tempat wisata di Ciayumajakuning.

3. Dengan penerapan teknologi markerless augmented reality, aplikasi ini dapat menginformasikan keberadaan POI sesuai dengan posisi sebenarnya. Karena dengan teknologi ini, aplikasi dapat menunjukkan posisi POI berada sesuai dengan interaksi user pada aplikasi terhadap lingkungan di sekitarnya.

\subsection{Saran}

Tentunya aplikasi yang dibangun ini masih jauh dari kata sempurna dan masih memiliki banyak kekurangan. Untuk itu, perlu dilakukan pengembangan dan penyempurnaan lebih lanjut. Adapun saran agar aplikasi ini bisa berjalan dengan lebih optimal dan lebih menarik sebagai berikut:

1. Fasilitas umum dan lokasi wisata yang di informasikan masih kurang dan hanya terbatas pada beberapa lokasi wisata saja. Sehingga dapat dikembangkan lagi.

2. Penerapan direction map dapat dikembangkan menjadi visualisasi augmented realty dengan objek garis sebagai penuntunnya ke arah yang akan dituju.

3. Marker augmented reality dapat dikembangkan lagi menjadi lebih interaktif sehingga menjadi lebih menarik.

4. Penambahan fitur-fitur baru pada aplikasi.

5. Aplikasi dapat digunakan pada perangkat bergerak lainnya yang mempunyai sistem operasi tersendiri seperti Iphone, Blackberry, dan Windows Phone.

\section{DAFTAR PUSTAKA}

[1] Akbar, T. (2012). Implementasi Augmented Reality dengan Memanfaatkan GPS Based Tracking pada Pembangunan Aplikasi Bandung Tour Guide Berbasis Platform Android. Makalah Seminar Tugas Akhir.

[2] Djamaludin, dan Usino, W, (2014). Protipe Sistem Informasi Pencarian Lokasi pusat Kesehatan Masyarakat Berbasis SIG di Kota Tanggerang. Jurnal Teknik Informatika Universitas Islam Syekh Yusuf. ISSN:2252-5351

[3] Fikri, I. A., Herumurti D., dan Rahman, R.H. (2016). Aplikasi Navigasi Berbasis Perangkat Bergerak dengan Menggunakan Platform Wikitude untuk Studi Kasus Lingkungan ITS. JURNAL TEKNIK ITS Vol. 5, No. 1. ISSN: 2337-3539/23019271

[4] Fowler, Martin. (2004). UML Distiled Edisi 3 Panduan Singkat Bahasa Pemodelan Objek Standar (Terjemahan Tim Penerjemah Penerbit Andi). Yogyakarta: Andi. 
[5] Hatmoko, B.D. (2014). Sistem Informasi Obyek Wisata (Tour Guid) Secara Real Time Menggunakan GPS di Bogor Via Mobile Android. Faktor Exacta 7(1): 5971. ISSN: 1979-276X

[6] Haviluddin. (2011) Memahami Penggunaan UML (Unified Modelling Language). Jurnal Informatika Mulawarman Vol 6 No. 1 Febuari 2011

[7] Hidayat, A. A., Kholil, M., Winda, dan Yudistira, (2015). Analisis Tingkat Kepuasan Pelanggan Sebagai upaya Peningkatan Nilai Tambah Terhadap Jasa Cleaning Service. Seminar Nasional IENACO. ISSN 2337-4349

[8] Hollerer, Tobias H., K, Steven., (2004). Location-Based Computing and Services, Chapter 9 - Mobile Augmented Reality, Francis Books Ltd., 01/2004.

[9] Juansyah, A. (2015). Pembangunan Aplikasi Child Tracker Berbasis Asissted Global Positioning System (A-GPS) dengan Platform Android. Jurnal Ilmiah Komputer dan Informatika (KOMPUTA) Edisi. 1 Volume. ISSN : 2089-9033

[10] Milgram, Paul, Kishino, Fumio, (1994). Augmented Reality : A class of displays on the reality-virtuality cintinuum, Japan: ATR Communication System Reseach Laboratories.

[11] Piarsa, N., I., Buana, W., P., (2016). Android Navigation Application with Location-Based Augmented Reality. IJCSI International Journal of Computer Science Issues, Volume 13, Issue 4. ISSN (Print): 1694-0814 | ISSN (Online): 1694-0784

[12] Ramdhon, A., N. (2014). Aplikasi Pemandu Wisata Kebun Binatang Bandung Berbasis Android. Makalah Seminar Tugas Akhir.

[13] Rozaldi, F. R. (2015). Implementasi Augmented Reality pada Aplikasi Pemandu Kota Menggunakan Metode Location Service Berbasis Android. Makalah Seminar Tugas Akhir.

[14] Santoso Nurdin, (2014). Pembangaunan Augmented Reality Denah Museum Geologi Bandung Menggunakan Metode Markerless Berbasis Android. Makalah Seminar Tugas Akhir

[15] Saputro, H. (2012). Modul Pembelajaran Praktek Basis Data (MySQL).

[16] Sari, J., P. (2014). Rancang Bangun Aplikasi Layanan Berbasis Lokasi Dengan Penerapan Augmented Reality Menggunakan Metode Markerless Berbasis Android. Jurnal Rekursif, Vol. 2 Nomor 2 November 2014, ISSN 2303-0755

[17] Wibisono, W., Baskoro, F., (2002). Pengujian Perangkat Lunak dengan Menggunakan Model Behavior UML. JUTI, Vol.1, nomor 1. Juli 2002: 43-50, ITS Surabaya. 
